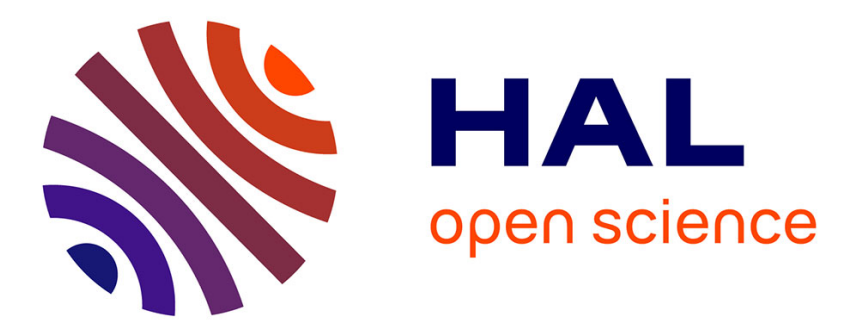

\title{
Influence of quench rate and microstructure on bendability of AA6016 aluminium alloys
}

Philippe Castany, Frédéric Diologent, Andreas Rossoll, Jean-François Despois, Cyrille Bezençon, Andreas Mortensen

\section{- To cite this version:}

Philippe Castany, Frédéric Diologent, Andreas Rossoll, Jean-François Despois, Cyrille Bezençon, et al.. Influence of quench rate and microstructure on bendability of AA6016 aluminium alloys. Materials Science and Engineering: A, 2013, 559, pp.558-565. 10.1016/j.msea.2012.08.141 . hal-00763170

\section{HAL Id: hal-00763170 \\ https://hal.science/hal-00763170}

Submitted on 20 Feb 2014

HAL is a multi-disciplinary open access archive for the deposit and dissemination of scientific research documents, whether they are published or not. The documents may come from teaching and research institutions in France or abroad, or from public or private research centers.
L'archive ouverte pluridisciplinaire HAL, est destinée au dépôt et à la diffusion de documents scientifiques de niveau recherche, publiés ou non, émanant des établissements d'enseignement et de recherche français ou étrangers, des laboratoires publics ou privés. 
Influence of quench rate and microstructure on bendability of AA6016 aluminium alloys

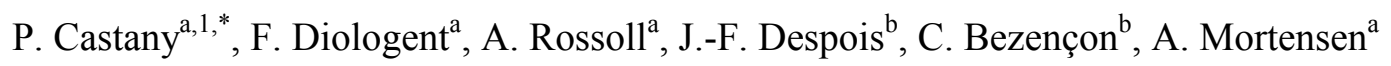

${ }^{a}$ Laboratoire de Métallurgie Mécanique, Institut des Matériaux, Station 12, Ecole

Polytechnique Fédérale de Lausanne, 1015 Lausanne, Switzerland

${ }^{\mathrm{b}}$ Novelis Switzerland SA, 3960 Sierre, Switzerland

\begin{abstract}
The influence of the quench rate after solution treatment on the bendability of AA6016 aluminium alloy sheets was investigated. Crack initiation during bending tests is found to be independent of quench rate whereas crack propagation is decreased after rapid quenching. A quantitative analysis of microstructures was carried out by transmission electron microscopy, focusing on grain boundary precipitates to correlate bending properties with microstructure. Crack initiation occurs by voiding at large micron-size intermetallic AlFeSi particles in shear bands, as previously proposed in the literature. Rapid quenching promotes the formation along grain boundaries of spherical $\mathrm{Mg}_{2} \mathrm{Si}$ precipitates to the detriment of elongated $\mathrm{Si}$ precipitates that dominate after slow cooling. These Si grain boundary precipitates affect micro-voiding processes that drive crack propagation, which explains the observed dependence of the extent of cracking on quench rate. The grain boundary precipitate density has on the other hand no effect on crack initiation or propagation.
\end{abstract}

*Corresponding author.

E-mail addresses: philippe.castany@insa-rennes.fr (P. Castany); andreas.mortensen@epfl.ch (A. Mortensen)

${ }^{1}$ Present address: INSA de Rennes, UMR CNRS 6226 Sciences Chimiques de Rennes/Chimie-Métallurgie, 20 avenue des Buttes de Coësmes, 35708 Rennes Cedex 7, France 
Keywords: aluminium alloy; bendability; microstructure; grain boundary precipitates; transmission electron microscopy.

\section{Introduction}

Heat-treatable Al-Mg-Si alloys of the 6xxx series are used for automotive body panels because of their low specific density and their comparatively good formability. Such aluminium alloy sheets are usually shaped in the T4 state (after solution treatment) while precipitation hardening is generally performed after forming during the paint-bake process. The formability of Al-Mg-Si alloys sheets in the T4 state is thus of key importance in this class of applications.

Large AlFeSi intermetallic particles are known to have a detrimental effect on the formability of 6xxx series aluminium alloys. AlFeSi intermetallics favour crack initiation [1-7]: during deformation, intermetallic particles situated along shear bands initiate voiding which, in turn, promotes shear crack formation. These larger intermetallic particles are generally formed during homogenization of as-cast ingots and do not dissolve when the alloy is further heat treated. Their size is typically above $1 \mu \mathrm{m}$. In Al-Mg-Si alloys, intermetallic particles are mainly $\beta$-AlFeSi and $\alpha$-AlFeSi. The $\beta$ particles are of $\mathrm{Al}_{5} \mathrm{FeSi}$ and have a monoclinic structure [8-11]. The $\alpha$ phase has a cubic structure; its composition is not clearly established [8,9,11-13]. The $\alpha$ particles have a more globular morphology than the interconnected platelike $\beta$ particles, which are known to degrade the formability of these alloys by promoting the formation of voids during deformation $[7,8,14,15]$. The formability can thus be improved by promoting the formation of $\alpha$ particles instead of $\beta$ particles when the alloy is homogenized; 
this can be accomplished by increasing the temperature and/or time of homogenization $[10,14,15]$ or by adding $\alpha$-stabilizer elements such as Mn $[8,15-18]$. Regardless of particle type, alloys with a high content of $\mathrm{Fe}[2,3,5,19-21]$ or $\mathrm{Si}[20,22,23]$ are generally recognized to have a poorer formability due to a higher quantity of intermetallic particles; however, we note that Davidkov et al. considered recently that large micron-size $\mathrm{Mg}_{2} \mathrm{Si}$ particles formed on grain boundaries are the critical parameter promoting fracture of alloy AA6016 during bending, rather than large AlFeSi intermetallic particles [24].

Smaller particles are also formed during heat treatment and following cooling, especially during solutionizing. Depending on alloy composition, $\mathrm{Mg}_{2} \mathrm{Si}$ or Si particles about $100 \mathrm{~nm}$ wide can be found in $6 \mathrm{xxx}$ series aluminium alloys $[8,11,12,18]$. Their presence can be reduced with increased solution treatment time [25] or subsequent cooling rate [4,26]. No clear correlation between bendability and the type and proportion of grain boundary (GB) precipitates is established; some authors consider that these have no effects on bendability [6]. There are data to show that precipitation during natural (room-temperature) ageing of $\mathrm{T} 4$ alloys has an influence on bendability, causing it to decrease during storage $[19,22]$. This effect is strongest in the first days after solution treatment and then stabilizes after about one month of natural ageing [27].

No clear relationship between bendability and tensile properties is established: some studies show that bendability decreases when the yield strength increases $[5,28,29]$ while no correlation between these two parameters was found in other studies $[19,22]$. On the other hand, the bendability seems to be related to the reduction in area $(R A)$ at fracture after a tensile test. The bendability is commonly defined by the ratio $r_{\min } / t$ where $t$ is the thickness of the specimen and $r_{\min }$ the minimum radius to which the sample can be bent to $180^{\circ}$ before cracks are initiated at the surface. An empirical relationship between $R A$ and $r_{\min } / t$ was proposed by Datsko and Yang as [29]: 


$$
r_{\min } / t=C / R A-1
$$

where $C \approx 0.6-0.7$.

The bendability of $6 \mathrm{xxx}$ series aluminium alloys is very sensitive to several parameters such as temperature and time of homogenization or solution treatment, quench rate and composition, making the individual contribution of each parameter difficult to estimate. This paper aims to contribute to the question by investigating the influence of the quench rate after solution treatment on the bendability and microstructure of AA6016, a standard alloy for this class of applications. We place specific focus on grain boundary precipitates, aiming to identify their role in alloy bendability and crack propagation.

\section{Materials and experimental procedure}

The AA6016 alloy was provided by Novelis Switzerland SA in the form of sheets $1 \mathrm{~mm}$ thick having the composition given in Table 1 . The sheets were homogenized, hot rolled and then cold rolled. These were then solution treated at $840 \mathrm{~K}$ for $55 \mathrm{~s}$, and brought to room temperature by a water quench (WQ) or alternatively by air cooling (AC). These two types of T4 samples were then stored for one month at room temperature, to approximate industrial usage conditions. Thereafter, the alloys were stored at $255 \mathrm{~K}$ in order to avoid any variation in extent of natural ageing between samples of the study. All characterization was done on samples in one of these two T4 conditions (designated WQ or AC).

Tensile tests were conducted on flat specimens at a strain rate of $1.8 \times 10^{-4} \mathrm{~s}^{-1}$, testing four samples per condition. Bending tests were conducted on a custom-made device meeting requirements of the ASTM E290 standard [30]. Bend test specimens had a $20 \mathrm{~mm} \times 70 \mathrm{~mm}$ rectangular shape with a thickness $t=1 \mathrm{~mm}$ and the sample long dimension parallel to the 
rolling direction. During the bend test these specimens were supported on two fixed cylindrical supports (no rotation possible) and were bent between the two supports to an angle of $180^{\circ}$ by applying force with a plunger; Fig. 1 gives a drawing of the set-up. Plungers with a radius $r$ of $0.1,0.2,0.3,0.4$ or $0.5 \mathrm{~mm}$ were used to impose different bend radii. The distance between the two supports depends on the radius of the plunger used and is given by the relation: $2 r+3 t$, where $r$ is the radius of the plunger and $t$ the thickness of the specimen (1 $\mathrm{mm}$ here). The velocity of the plunger is fixed at $6 \mathrm{~mm} / \mathrm{min}$. The outer surface of specimens thus bent to $180^{\circ}$ were then examined for the presence of cracks. The minimum bend radius $r_{\min }$ is then defined as the smallest radius among the above values for which the surface of the $180^{\circ}$ bent specimen evidences no cracks. The bendability is next quantified by the ratio $r_{\min } / t$ where $t$ is the thickness of the specimen. For the two T4 conditions, two tests were carried out per bend radius for each $\mathrm{T} 4$ condition.

The microstructure was characterized by transmission electron microscopy (TEM) using a Philips CM20 microscope operating at $200 \mathrm{kV}$. Thin foils were $3 \mathrm{~mm}$ diameter disks obtained by electro-discharge machining from the $1 \mathrm{~mm}$ thick $\mathrm{T} 4$ sheets. These were thinned down to $80 \mu \mathrm{m}$ using $\mathrm{SiC}$ abrasive papers and then twin-jet electropolished at $253 \mathrm{~K}$ using a solution of $15 \%$ perchloric acid and $85 \%$ methanol (vol. \%).

Grain boundary precipitates were studied via TEM. In order to estimate the surface density of precipitates along grain boundaries, the area of each observed grain boundary surface was measured as $b \times L$, where $b$ and $L$ are respectively the width and length of the grain boundary contained within the thinned TEM specimen (Fig. 2). $L$ was measured directly on TEM micrographs together with the projected length $d_{a p p}$ of $b$ on TEM micrographs (Fig. 2). The value of $b$ was then deduced from $d_{a p p}$ and the thickness of the thin foil $h$ with the relation: $b$ $=\left(d_{a p p}{ }^{2}+h^{2}\right)^{1 / 2}$. The thickness $d_{a p p}$ of the TEM foil locally in the vicinity of each grain boundary was in turn measured from thickness fringes on inclined grain boundaries observed 
in the Bragg condition [31]. Using this method, the thin foil thickness and, hence, $b$ and the grain boundary area were estimated with an accuracy of about $10 \%$. For each of the two T4 alloys (WQ and AC), the surface density of precipitates along grain boundaries was measured over a total grain boundary surface area of about $70 \mu \mathrm{m}^{2}$ corresponding roughly to one hundred precipitates for either quench rate.

\section{Results}

\subsection{Mechanical testing}

Tensile test data are summarized in Table 2. Figure 3 shows a typical tensile curve for each condition. As seen, differences are slight; however, the yield strength $\left(R_{0.2}\right)$ and tensile strength $\left(R_{\max }\right)$ are somewhat higher for the WQ samples whereas both WQ and AC samples exhibit the same elongation at failure $\left(\varepsilon_{\max }\right)$. The reduction in area $(R A)$, approximated by the local thin-section reduction in thickness of the flat tensile specimens upon failure $[5,19,22]$, was also similar for the two conditions.

The bendability of the sheets was quantified by observation of the outer surface of bent samples. Figure 4 shows the surface of both AC and WQ samples bent to $180^{\circ}$ with different bend radii. Surface cracking starts with $r=0.3 \mathrm{~mm}$ for both AC and WQ samples; hence both conditions have the same bendability $r_{\min } / t=0.4$. On the other hand, the surface of AC samples is more damaged than WQ samples when $r$ drops below $r_{\min }$; in other words, for $r=$ 0.2 and $0.1 \mathrm{~mm}$, cracking is more extensive for the AC condition (Fig. 5). Particularly for $r=$ $0.1 \mathrm{~mm}$, cracks have propagated across the entire thickness of the AC sample while in the WQ sample cracking remains confined to the outer surface. 
Figure 6 shows a Scanning Electron Microscope (SEM) image of a sample surface after bending, here for an AC sample bent with $r=0.3 \mathrm{~mm}$. Cracks are shown to develop in the "valleys" of the surface, which has roughened due to strain localization (this being likely induced by grain orientation effects). WQ samples exhibit the same topology of crack initiation sites.

In summary, (i) the quench rate has no effect on crack initiation and, hence, on bendability as usually defined, while (ii) for the same bend radius, crack propagation is easier for a low quench rate (AC) than after rapid quenching (WQ).

\subsection{Microstructure}

Figure 7 shows TEM micrographs of large micron-size AlFeSi intermetallic particles in AC and WQ samples. Figure 7a is an example of one of the largest such particles observed, while Fig. $7 \mathrm{~b}$ is an example of one of the smallest found. The same type of particle (morphology, size) is observed in both AC and WQ samples. Large particles are found within grains as well as at grain boundaries.

Inside the grains of AC and WQ samples, the microstructure is similar. It features nearspherical precipitates (Fig. 8) of diameter ranging between 50 and $250 \mathrm{~nm}$; these are presumed to be $\mathrm{Mg}_{2} \mathrm{Si}$. Some dislocations are also present. Their density seems to be somewhat higher in WQ samples (Fig. 8a) than in AC samples (Fig. 8b).

Numerous precipitates are observed along grain boundaries (GB). General views of GBs are shown in Fig. 9 for the WQ condition and in Fig. 10 for the AC condition. Two precipitate morphologies are found: spherical precipitates (example in Fig. 11a for a WQ sample) and irregular-shaped precipitates, which are usually elongated (example in Fig. 11b for an AC sample). Selected area electron diffraction (SAED) analyses show that the spherical 
precipitates are $\mathrm{Mg}_{2} \mathrm{Si}$ while the elongated precipitates are pure Si. This correlation between shape and type of precipitates is in agreement with previous results [11]. These two types of precipitates are observed in both AC and WQ samples. Their average sizes are given in Table 3: the diameter of $\mathrm{Mg}_{2} \mathrm{Si}$ spherical precipitates is slightly larger in WQ samples than in $\mathrm{AC}$ samples, while the elongated Si precipitates are clearly longer and thinner in AC samples than in WQ samples.

In some grain boundary areas, very small precipitates about ten nanometres in diameter are also observed, Fig. 11c. Such areas are more frequently observed for the WQ condition than the AC condition. Compositional characterization of these precipitates was not possible due to their small size; these, however, are most probably $\mathrm{Mg}_{2} \mathrm{Si}$ given their spherical shape. In quantitative analysis of grain boundary precipitate density, outlined below, these very small precipitates were not taken in account.

To determine the density of precipitates along grain boundaries, the total grain boundary area observed was first deduced from measurements of the thin foil thickness (see Section 2 for details). The surface density of precipitates along grain boundaries was then determined by counting: there are 1.4 precipitates per $\mu \mathrm{m}^{2}$ for the WQ condition and 1.5 precipitates per $\mu \mathrm{m}^{2}$ for the AC condition. Taking into account the attainable precision of measurement, we conclude that the average surface density of precipitates along grain boundaries is the same for AC and WQ conditions.

On the other hand, the distribution of precipitates differs strongly between the two quench conditions, Table 4: $72 \%$ of GB precipitates are spherical $\mathrm{Mg}_{2} \mathrm{Si}$ precipitates in WQ samples while these are only $31 \%$ of GB precipitates observed in AC samples. The ratio between spherical and elongated precipitates is inverted for both quench rates: a rapid quench rate (WQ) favours the formation of spherical $\mathrm{Mg}_{2} \mathrm{Si}$ GB precipitates whereas a slow quench (AC) favours the formation of elongated Si GB precipitates. 
While the number of precipitates per unit area of GB is the same, the grain boundary surface area covered by precipitates also differs between WQ and AC samples (Table 4). The GB surface covered by precipitates in $\mathrm{AC}$ samples (5.2\% of the total grain boundary area observed) is more than twice the surface covered in WQ samples (2.2\%). This difference is mainly due to the larger proportion and size of elongated Si precipitates in the AC condition. In summary, although the same grain boundary precipitate density is measured for both quench rates, the proportion of elongated Si precipitates is higher after air cooling than after a water quench; furthermore, these precipitates have a higher aspect ratio and length in the AC condition. Also, a larger percentage of the grain boundary area is covered by precipitates in AC samples, this mainly being due to coverage by elongated Si precipitates.

\section{Discussion}

The microstructures observed in this study are in agreement with previous observations on AA6016 alloys or alloys with similar composition. In Al-Mg-Si alloys, the $\mathrm{Mg} / \mathrm{Si}$ ratio is commonly used to determine the amount of excess $\mathrm{Si}$ present in the $\mathrm{Al}$ matrix after all $\mathrm{Mg}$ is consumed in $\mathrm{Mg}_{2} \mathrm{Si}$ precipitates. The AA6016 alloy of this study has a large excess of silicon with a $\mathrm{Mg} / \mathrm{Si}$ mass ratio of 0.37 (the $\mathrm{Mg} / \mathrm{Si}$ mass ratio is 1.73 for $\mathrm{Mg}_{2} \mathrm{Si}$ ). In alloys with excess $\mathrm{Si}$, pure Si particles are known to precipitate [8,11,32-34], and have previously been observed as nanometric-size grain boundary particles [25]. Nanometric-size $\mathrm{Mg}_{2} \mathrm{Si}$ particles are also commonly observed in T4 conditions, both along grain boundaries $[25,26]$ and within grains [35].

Large micron-size AlFeSi intermetallic particles are also expected; these were observed for both quenching conditions, with no difference found between the two quench conditions. As 
such AlFeSi particles are formed during or before homogenization of as-cast ingots $[1,8,9,12,14,15]$, it makes sense that their size and distribution be identical for both AC and WQ samples.

The two quench rates explored here thus yield broadly similar microstructures; however, as shown here, differences exist as concerns grain boundary precipitation: about $70 \%$ of GB precipitates are spherical $\mathrm{Mg}_{2} \mathrm{Si}$ precipitates and about 30\% are elongated Si precipitates for the WQ condition, whereas the ratio between these two types of precipitates is exactly inverted for the AC condition. Furthermore, in the AC condition, Si precipitates are longer, have a higher aspect ratio, and cover a greater portion of the grain boundary area.

The two quench conditions produce sheets with the same value of bendability, namely 0.4 : cracks appear at the same $r$. The phenomenon that initiates cracking is thus independent of quench rate. A likely explanation is that the onset of cracking is due to texture-induced strain localization enhanced by the presence of large intermetallics particles. This explanation is consistent with the usual view that considers cracks to be initiated around large intermetallics particles within shear bands that form while these alloys are subjected to bending (see Introduction) $[2,3,5-7,19,21,23,26,36,37]$. Neither grain structure nor intermetallic particles being influenced by the cooling rate, this is consistent with present data.

We also note that, using Eq. (1) and the measured tensile reduction in area at failure (about $70 \%$ ), the bendability is calculated to be 0 , which compares poorly with the presently measured bendability value (0.4): the relationship in Eq. (1) seemingly only works for specific conditions and compositions $[5,19,22]$. In addition, the yield strength is higher for the WQ condition than for the AC condition with no clear difference in bendability, leading to conclude that there is no single correlation between tensile properties and bendability as previously proposed for some AlMgSi alloys [5,28]. 
While cracks are initiated during bending at the same amount of deformation, their propagation is clearly easier in the AC condition, Fig. 5. The only significant difference in microstructure was found in the nature and extent of grain boundary precipitation. This leads to conclude that the grain boundary structure exerts a significant influence on crack growth during bending of Si-rich AA6016 aluminium sheet. That crack propagation is related to GB precipitates was previously observed or suggested for other alloys $[5,25,26,28]$; however, the parameter favouring crack propagation was not established. Moreover, it was shown that GB precipitates favour crack propagation by promoting void coalescence, even when fracture is not intergranular [38].

Microstructure and crack propagation rate are often linked by the interparticle distance: a larger interparticle distance implies a larger distance between voids that are nucleated by particle cracking or debonding, in turn raising the fracture toughness $[39,40]$. In the present material, however, the density and therefore the distance between particles is the same for the two heat treatments; this parameter therefore does not explain the difference between the two quench conditions.

This leaves the nature and shape of grain boundary precipitates as key parameters governing crack propagation in this alloy as a function of cooling rate: quenching decreases the fraction and the aspect ratio of larger silicon particles situated along grain boundaries. This in turn reduces the grain boundary areal coverage by brittle second phases by a factor near two (from 5.2 to $2.2 \%$ ). That the shape and grain boundary areal coverage by these particles, together with the particle nature, influence crack growth broadly agrees with parallel observations in the literature concerning the role of intermetallic particles. In this class of alloy, micron-size $\alpha$ intermetallic particles are known to cause less voiding than $\beta$ particles during bending because of their more spherical morphology $[8,16,17]$, which parallels the present observation that replacing GB spherical particles with high aspect ratio Si particles is detrimental. That 
grain boundary precipitation governs the bend crack resistance of AA6016 sheet also agrees with observations in Ref. [24], where it is documented that increasing the proportion of micron-size grain boundary $\mathrm{Mg}_{2} \mathrm{Si}$ particles in Si-rich AA6016 alloys causes a reduced resistance to grain boundary fracture during bending. Alloy compositions differ somewhat with the present study, and most importantly the temperature of the solution treatment is not given in Ref. [24]; hence, a comparison with the present study (where Si particles are shown to have the dominant deleterious influence on crack growth resistance and such large $\mathrm{Mg}_{2} \mathrm{Si}$ GB particles were not found) cannot be carried further.

It remains to be asked why the GB precipitates would influence crack propagation but not crack initiation. A possible explanation is that these two processes are governed by phenomena that operate on different scales, in terms of both length and stress. Crack initiation occurs at the sample surface, apparently by strain localization induced by grain orientation effects and enhanced by the presence of larger intermetallics. Localization of plastic deformation in shear followed by crack initiation is promoted by crystal texture and by the presence of large intermetallic particles, see e.g. Refs. [5,36,37]. This stage should be identical for both heat treatments, since the relevant microstructural features are identical. Once a crack is initiated, on the other hand, ahead of its tip the stress level and triaxiality are raised significantly, while the average length scale of damage processes is much smaller than the average alloy grain size. Near a crack tip, larger elongated Si GB precipitates present in the $\mathrm{AC}$ condition of the material thus likely play a role, by cracking and thereby promoting crack growth, while these are too small or too strong to initiate crack formation.

In summary, the present study suggests the following correlation between bending properties of Si-rich AA6016 and the quench rate after solutionizing at $840 \mathrm{~K}$ :

(i) Cracks are initiated during bending due to strain localization resulting from grain orientation effects and probably promoted by larger micron-size intermetallic particles. Both 
the grain structure and intermetallics are not modified by the cooling rate; the bendability is therefore independent of the quench rate.

(ii) Grain boundary precipitates formed during quenching influence subsequent crack propagation. A rapid quench favours the formation of spherical $\mathrm{Mg}_{2} \mathrm{Si}$ GB precipitates while slow cooling favours the formation of elongated Si GB precipitates. The latter apparently are weaker in the vicinity of a crack tip than the former, such that cracks grow once formed to larger depths in bending for AC samples.

\section{Conclusions}

In AA6016 alloys, a rapid quench rate after solution treatment increases the tensile strength slightly but has no effect on bendability defined conventionally using the minimum bend radius. On the other hand, rapid quenching after solutionizing decreases significantly the extent of crack growth after bending to sharper radii.

Analyses of general microstructure and precipitation along grain boundaries lead to conclude that:

- the present data are consistent with the conventional view that during bending cracks are first initiated along shear bands at large intermetallic particles that are present in the alloy before quenching;

- a rapid quench promotes the formation of spherical $\mathrm{Mg}_{2} \mathrm{Si}$ precipitates roughly $100 \mathrm{~nm}$ in diameter along grain boundaries, while slower quenching favours the formation of more elongated Si GB precipitates;

- the number of precipitates per unit area of GB has no effect on crack initiation and propagation; 
- non-spherical Si precipitates formed along grain boundaries during slow quenching facilitate crack propagation during bending.

\section{Acknowledgements}

This research was funded by the Swiss Commission for Technology and Innovation (CTI).

Transmission electron microscopy was performed at the Interdisciplinary Centre for Electron Microscopy (CIME) at EPFL.

\section{References}

[1] H.D. Merchant, J.G. Morris, D.S. Hodgson, Mater. Charact. 25 (1990) 339-373.

[2] J. Sarkar, T.R.G. Kutty, D.S. Wilkinson, J.D. Embury, D.J. Loyd, Mater. Sci. Forum 331337 (2000) 583-588.

[3] J. Sarkar, T.R.G. Kutty, K.T. Conlon, D.S. Wilkinson, J.D. Embury, D.J. Lloyd, Mater. Sci. Eng. A 316 (2001) 52-59.

[4] M. Asano, H. Uchida, H. Yoshida, J. Jpn. Inst. Light Metal. 52 (2002) 448-452.

[5] J. Sarkar, T.R.G. Kutty, D.S. Wilkinson, J.D. Embury, D.J. Lloyd, Mater. Sci. Eng. A 369 (2004) 258-266.

[6] M. Asano, T. Minoda, Y. Ozeki, H. Yoshida, Mater. Sci. Forum 519-521 (2006) 771-776.

[7] D. Lassance, D. Fabregue, F. Delannay, T. Pardoen, Prog. Mater. Sci. 52 (2007) 62-129.

[8] M. Mulazimoglu, A. Zaluska, J. Gruzleski, F. Paray, Metall. Mater. Trans. A 27 (1996) 929-936.

[9] C.M. Allen, K.A.Q. O'Reilly, B. Cantor, P.V. Evans, Prog. Mater. Sci. 43 (1998) 89-170. 
[10] H. Tanihata, T. Sugawara, K. Matsuda, S. Ikeno, J. Mater. Sci. 34 (1999) 1205-1210.

[11] M.J. Couper, B. Rinderer, J.-Y. Yao, Mater. Sci. Forum 519-521 (2006) 303-308.

[12] F. Samuel, A. Samuel, H. Doty, S. Valtierra, Metall. Mater. Trans. A 32 (2001) 20612075.

[13] M. Janecek, M. Slamova, M. Cieslar, Kov. Mater.-Met. Mater. 42 (2004) 173-184.

[14] N.C.W. Kuijpers, J. Tirel, D.N. Hanlon, S. Van Der Zwaag, Mater. Charact. 48 (2002) 379-392.

[15] N.C.W. Kuijpers, F.J. Vermolen, C. Vuik, P.T.G. Koenis, K.E. Nilsen, S. Van Der Zwaag, Mater. Sci. Eng. A 394 (2005) 9-19.

[16] S. Zajac, B. Hutchinson, A. Johansson, L.-O. Gullman, Mater. Sci. Tech. 10 (1994) 323333.

[17] P. Zhao, J. Jpn. Inst. Light Metal. 55 (2005) 227-232.

[18] K.B.S. Couto, S.R. Claves, W.H. Van Geertruyden, W.Z. Misiolek, M. Goncalves, Mater. Sci. Tech. 21 (2005) 263-268.

[19] D.J. Lloyd, In: Symposium: Automotive Alloys 1999, San Diego (2000) 211-221.

[20] A. Hibino, T. Muramatsu, M. Saga, K. Takata, J. Jpn. Inst. Light Metal. 53 (2003) 534541.

[21] T. Minoda, M. Asano, H. Yoshida, Mater. Sci. Forum 519-521 (2006) 859-864.

[22] S.M. Hirth, G.J. Marshall, S.A. Court, D.J. Lloyd, Mater. Sci. Eng. A 319-321 (2001) 452-456.

[23] T. Minoda, M. Asano, H. Yoshida, J. Jpn. Inst. Light Metal. 55 (2005) 222-226.

[24] A. Davidkov, R.H. Petrov, P. De Smet, B. Schepers, L.A.I. Kestens, Mater. Sci. Eng. A 528 (2011) 7068-7076.

[25] M. Saga, M. Kikuchi, Y. Zhu, M. Matsuo, In: 6th International Conference on Aluminium Alloys, Toyohashi, Japan (1998) 425-430. 
[26] Y. Himuro, Z. Yong, K. Matsuda, S. Ikeno, K. Koyama, Y. Bekki, Mater. Forum 28 (2004) 464-469.

[27] G.B. Burger, A.K. Gupta, P.W. Jeffrey, D.J. Lloyd, Mater. Charact. 35 (1995) 23-39.

[28] G. Itoh, T. Suzuki, K. Horikawa, Mater. Sci. Forum 396-402 (2002) 1193-1198.

[29] J. Datsko, C.T. Yang, J. Eng. Ind. 82 (1960) 309-314.

[30] ASTM Standard E290, "Standard Test Methods for Bend Testing of Material for Ductility", ASTM International, West Conshohocken, PA, 2004, DOI: 10.1520/E0290-09, www.astm.org.

[31] D. Williams, C.B. Carter, Transmission Electron Microscopy, New York Plenum Press, 1996.

[32] D.J. Chakrabarti, D.E. Laughlin, Progr. Mater. Sci. 49 (2004) 389-410.

[33] A.K. Gupta, D.J. Lloyd, S.A. Court, Mater. Sci. Eng. A 316 (2001) 11-17.

[34] F. Lasagni, B. Mingler, M. Dumont, H.P. Degischer, Mater. Sci. Eng. A 480 (2008) 383391.

[35] A. Davidkov, R. Petrov, V. Bliznuk, P. Ratchev, P. De Smet, B. Schepers, L.A.I. Kestens, Key Eng. Mater. 465 (2011) 451-454.

[36] M. Dao, M. Li, Philos. Mag. A 81 (2001) 1997-2020.

[37] S. Ikawa, M. Asano, M. Kuroda, K. Yoshida, Mater. Sci. Eng. A 528 (2011) 4050-4054.

[38] M. De Haas, J.T.M. De Hosson, J. Mater. Sci. 37 (2002) 5065-5073.

[39] J.R. Rice, M.A. Johnson, In: Inelastic Behavior of Solids, M.F. Kanninen, W.A. Adler, A.R. Rosenfield et R.I. Jaffee Eds, McGraw-Hill, New York (1970) 641-672.

[40] G.T. Hahn, A.R. Rosenfield, Metall. Trans. A 6 (1975) 653-668. 


\section{Figure 1}

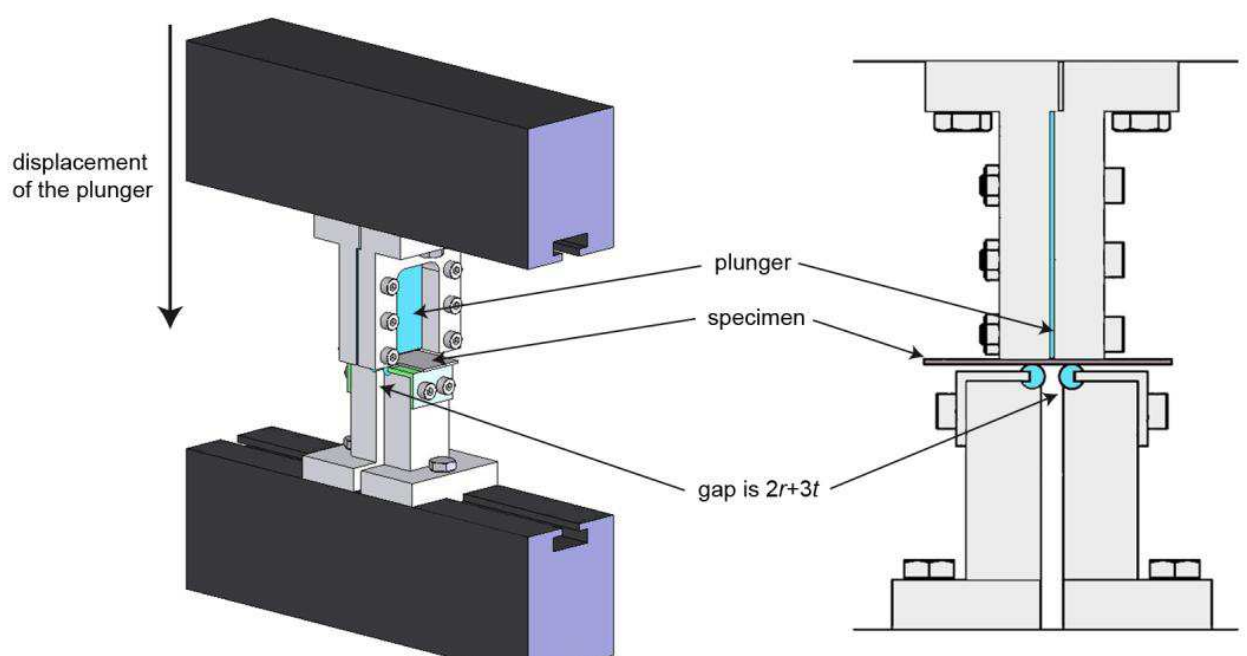

(a)

(b)

Fig. 1. General sketch of the bending device (a) and profile view (b). 
Figure 2

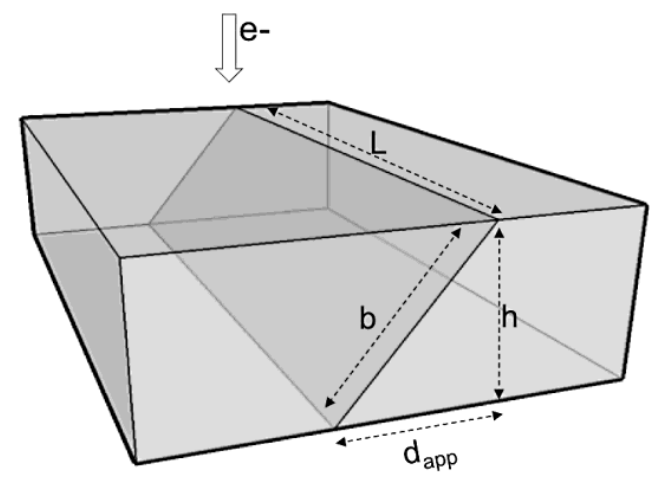

Fig. 2. Sketch of a thin foil with an inclined grain boundary (GB): the length $L$, the apparent width $d_{a p p}$ and the real width $b$ of the GB and the thickness of the foil $h$ are indicated. 
Figure 3

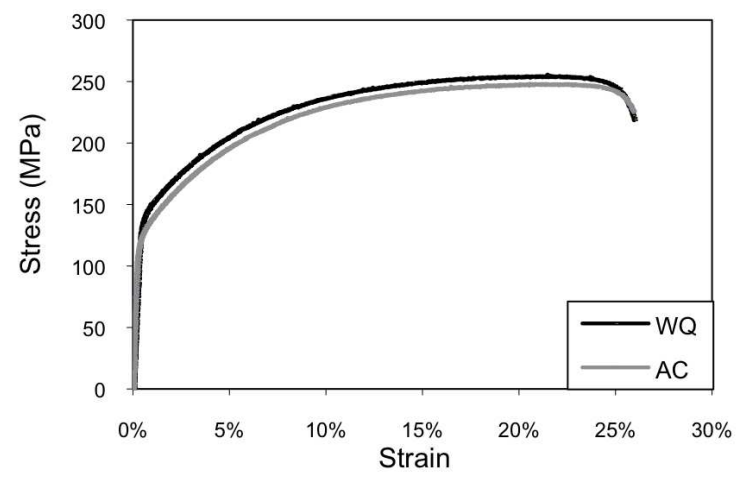

Fig. 3. Typical stress-strain curves of AC and WQ tensile specimens. 


\section{Figure 4}

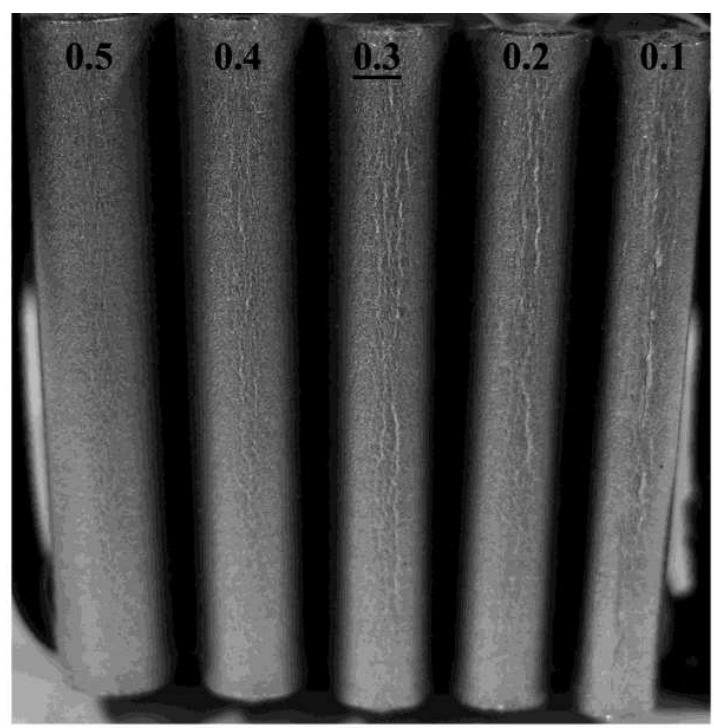

WQ

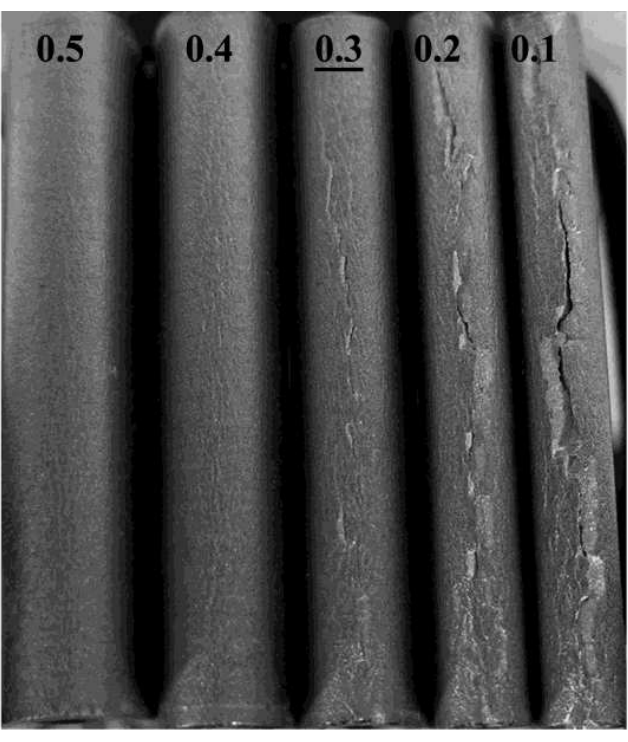

$\mathrm{AC}$

Fig. 4. Optical views of $180^{\circ}$ bent specimens without magnification (bend radii are indicated on the top of each image, with the underlined value indicating first crack apparition). 


\section{Figure 5}

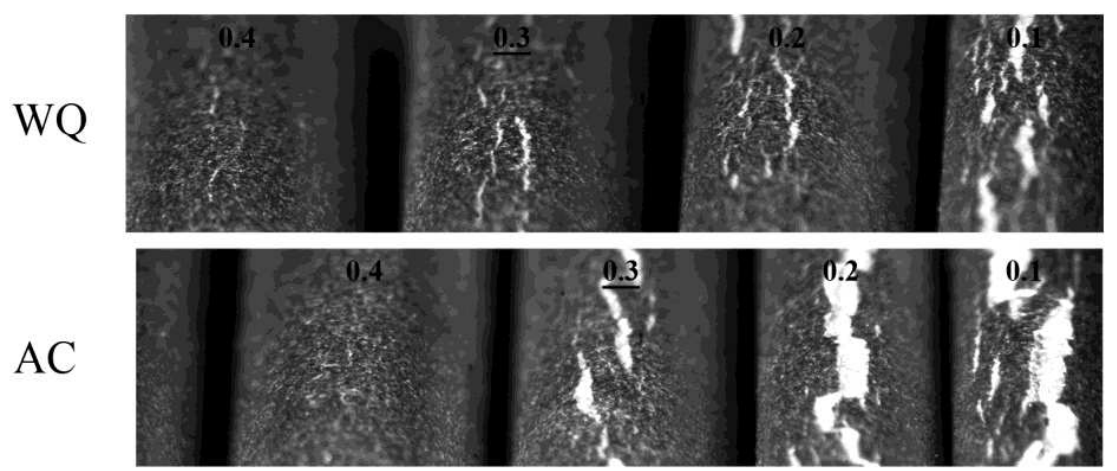

Fig. 5. Magnification of the bent surfaces of Fig. 4 showing details of damage. 


\section{Figure 6}

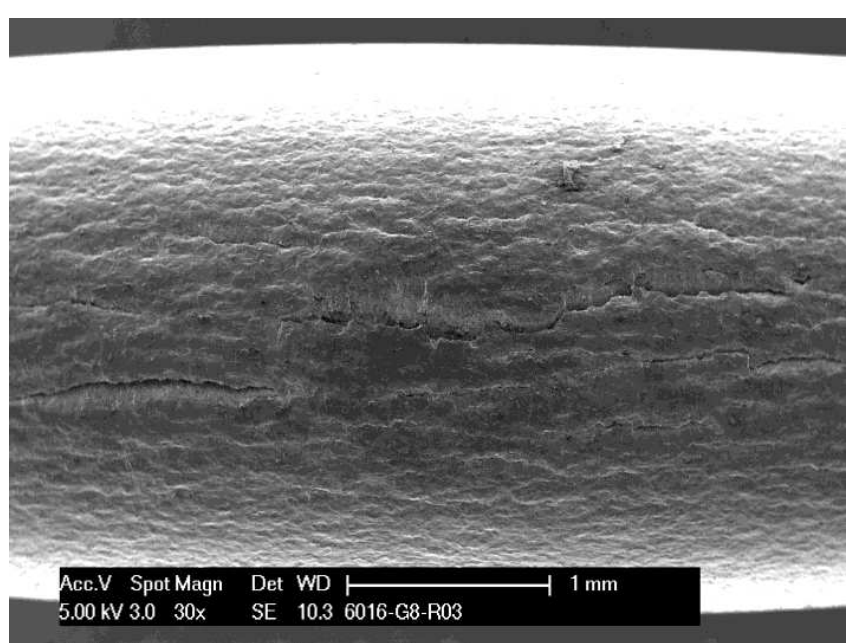

Fig. 6. SEM image of the surface of an AC sample after bending $(r=0.3 \mathrm{~mm})$. 


\section{Figure 7}
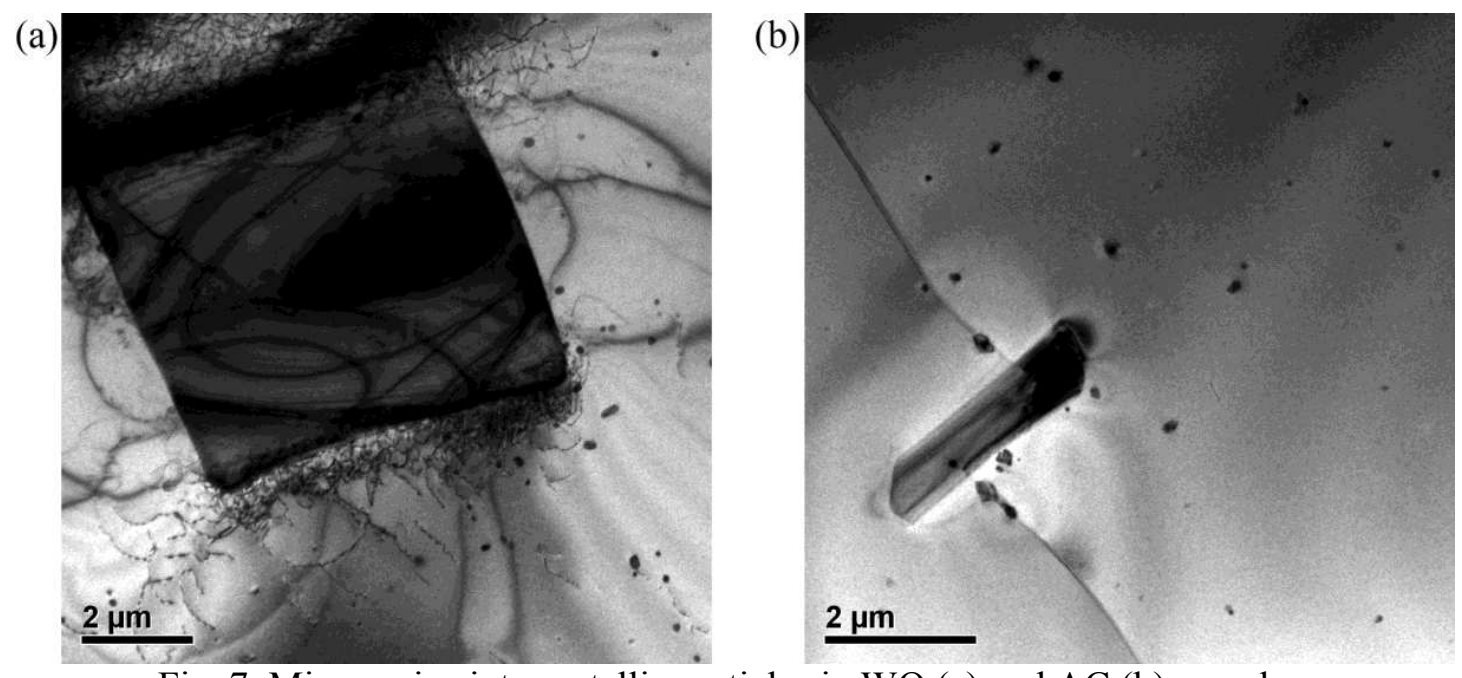

Fig. 7. Micron-size intermetallic particles in WQ (a) and AC (b) samples. 


\section{Figure 8}
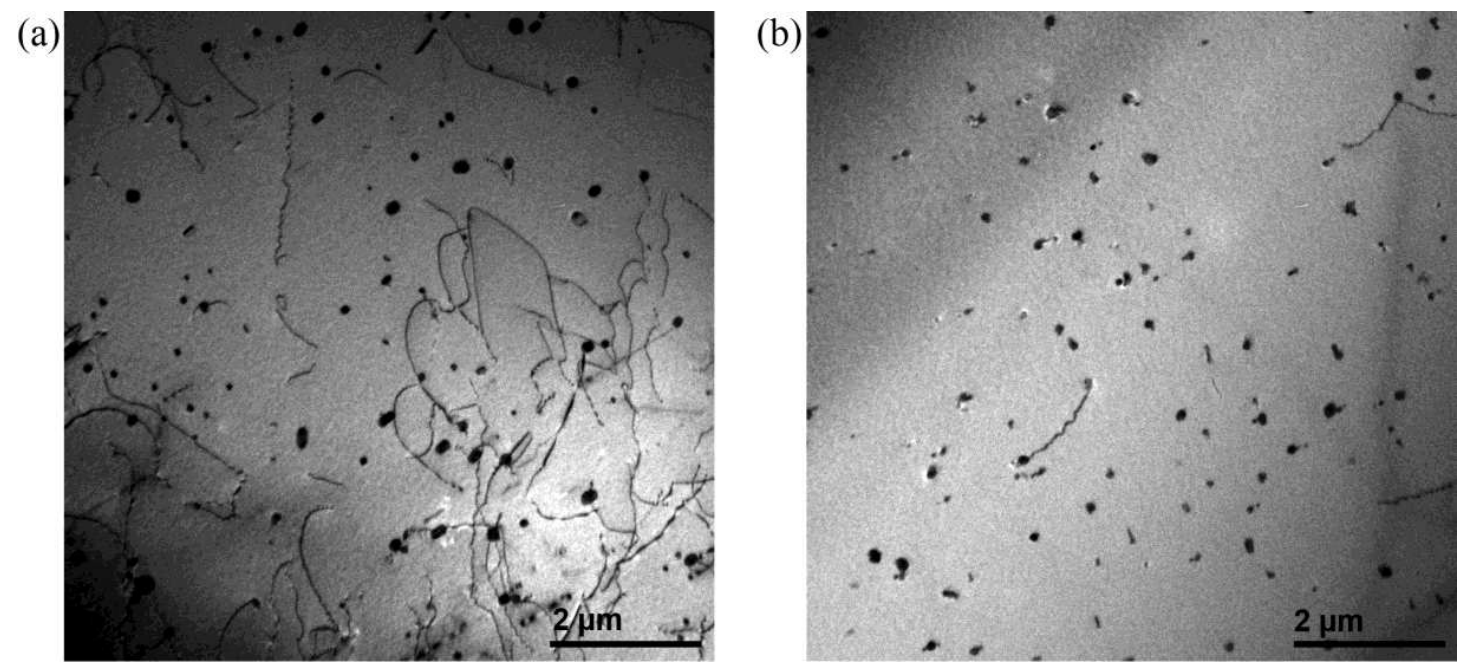

Fig. 8. Intragranular microstructure in WQ (a) and AC (b) samples. 


\section{Figure 9}

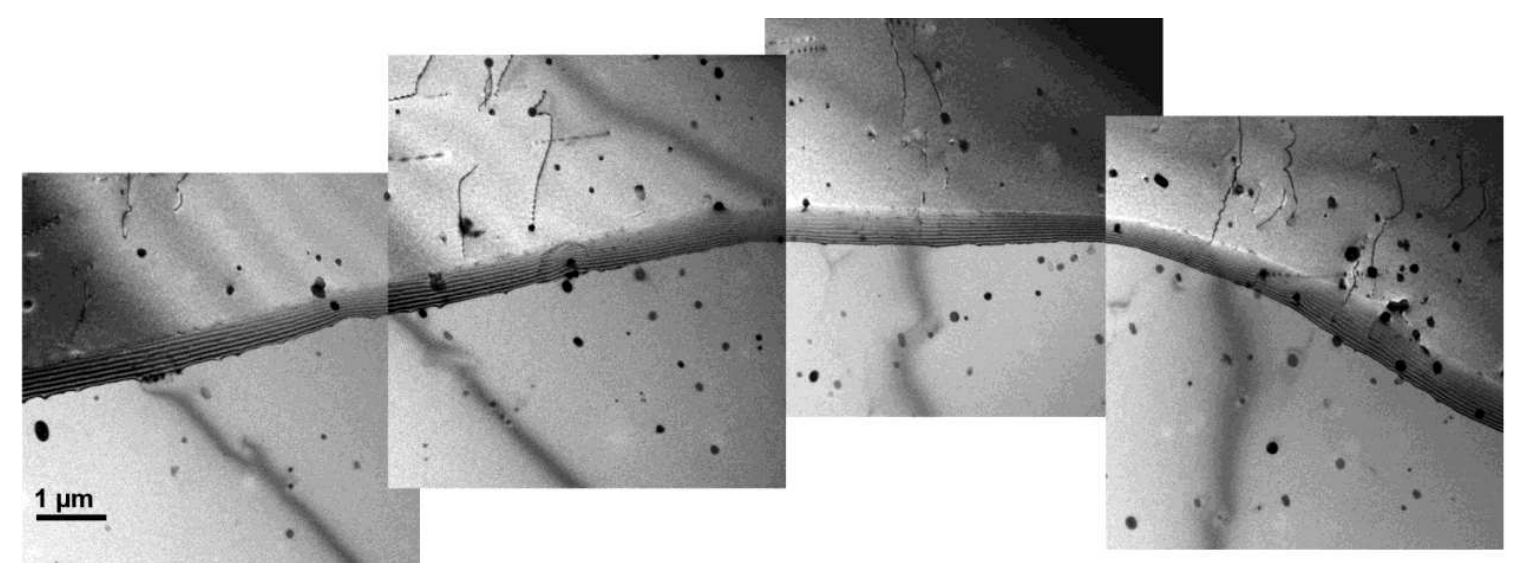

Fig. 9. TEM general view of a grain boundary in WQ sample with mainly spherical precipitates. 
Figure 10

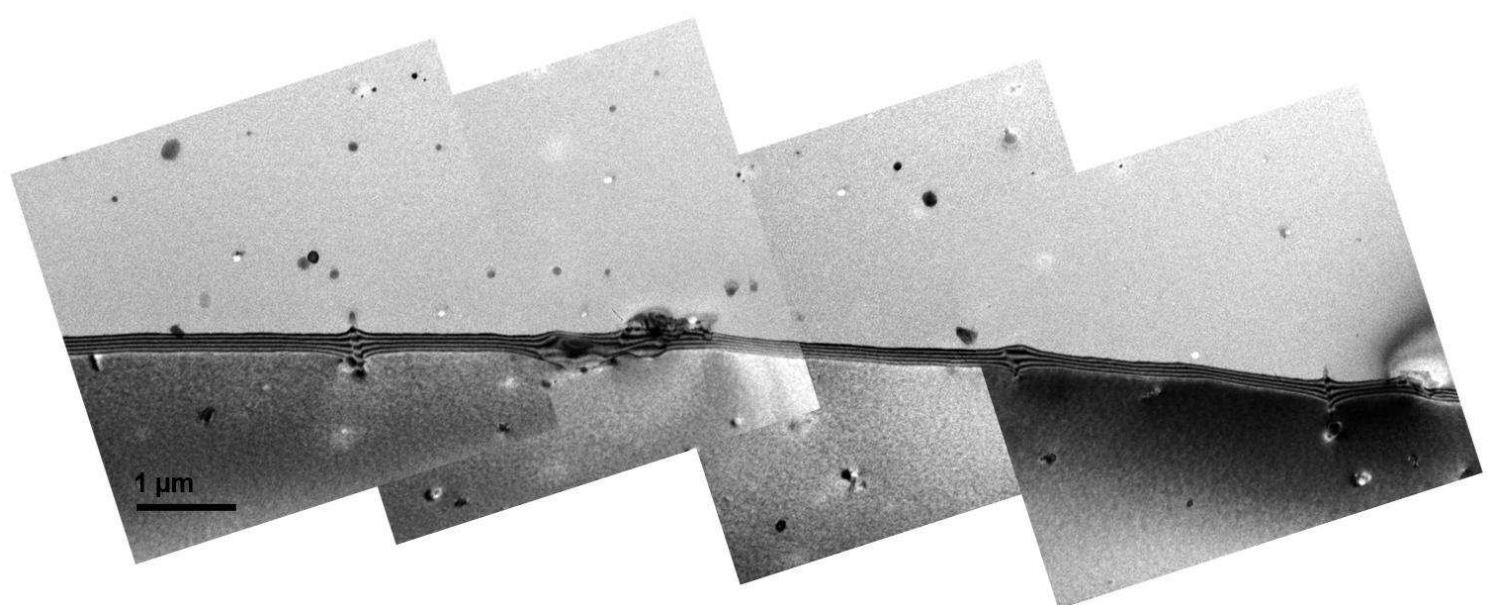

Fig. 10. TEM general view of a grain boundary in AC sample with mainly elongated precipitates. 


\section{Figure 11}

(a)

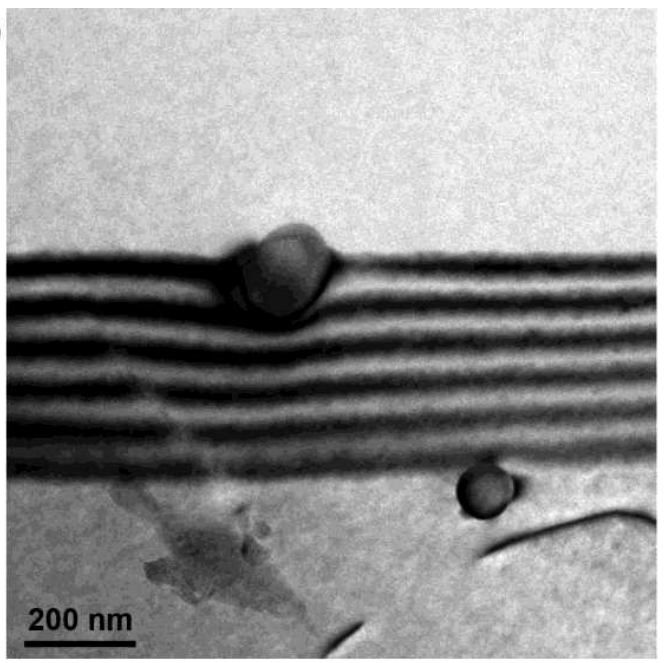

(b)

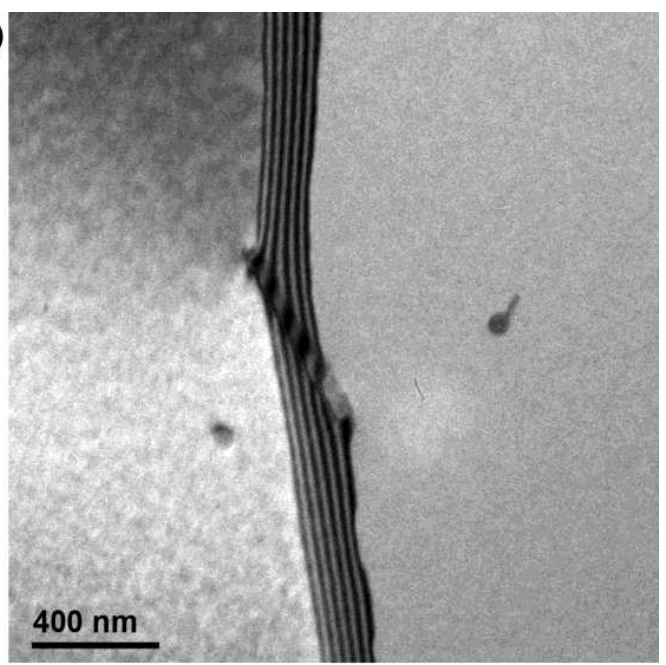

(c)

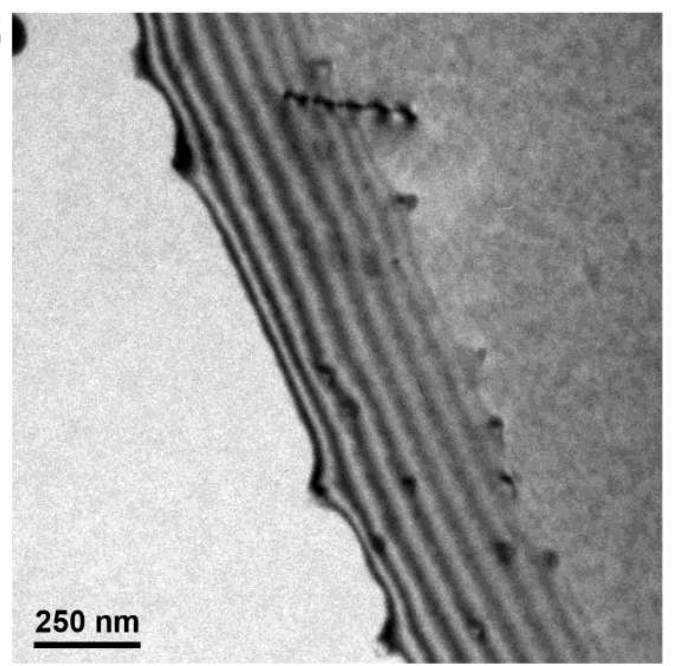

Fig. 11. Typical morphology of precipitates at grain boundaries: spherical $\mathrm{Mg}_{2} \mathrm{Si}$ in WQ sample (a), elongated Si in AC sample (b) and smaller spherical precipitates in WQ sample (c). 


\begin{tabular}{lcccccc}
\hline Alloy & $\mathrm{Si}$ & $\mathrm{Mg}$ & $\mathrm{Fe}$ & $\mathrm{Mn}$ & $\mathrm{Cu}$ & $\mathrm{Cr}$ \\
\hline AA6016 & 1.16 & 0.43 & 0.23 & 0.08 & 0.001 & 0.009 \\
\hline
\end{tabular}

Table 1. Chemical composition of the AA6016 alloy (weight percent). 


\begin{tabular}{lcccc}
\hline AA6016 & $\mathrm{R}_{0.2}(\mathrm{MPa})$ & $\mathrm{R}_{\max }(\mathrm{MPa})$ & $\varepsilon_{\max }$ & $\mathrm{RA}$ \\
\hline WQ & 134 & 256 & $26 \%$ & $71 \%$ \\
\hline $\mathrm{AC}$ & 121 & 248 & $26 \%$ & $72 \%$ \\
\hline
\end{tabular}

Table 2. Average results of tensile tests for the water quenched (WQ) and air cooled (AC) T4 AA6016 sheets. Standard deviations are $1 \mathrm{MPa}$ for $R_{0.2}$ and $R_{\max }, 1 \%$ for $\varepsilon_{\max }$ and $2 \%$ for $R A$. 


\begin{tabular}{lccc}
\hline AA6016 & $\begin{array}{c}\text { Diameter of spherical } \\
\text { precipitates }(\mathrm{nm})\end{array}$ & $\begin{array}{c}\text { Width of non-spherical } \\
\text { precipitates }(\mathrm{nm})\end{array}$ & $\begin{array}{c}\text { Length of non-spherical } \\
\text { precipitates }(\mathrm{nm})\end{array}$ \\
\hline WQ & 120 & 150 & 280 \\
\hline AC & 100 & 110 & 405 \\
\hline
\end{tabular}

Table 3. Size of precipitates on grain boundaries: the diameter of spherical precipitates and the width and length of the non-spherical ones are given. 


\begin{tabular}{lcccc}
\hline AA6016 & $\begin{array}{c}\text { Total surface of GB } \\
\text { covered by precipitates }\end{array}$ & $\begin{array}{c}\text { Proportion of spherical } \\
\text { precipitates }\end{array}$ & $\begin{array}{c}\text { Surface of GB covered by } \\
\text { spherical precipitates }\end{array}$ & $\begin{array}{c}\text { Total number of counted } \\
\text { precipitates }\end{array}$ \\
\hline WQ & $2.2 \%$ & $72 \%$ & $41 \%$ & 92 \\
\hline AC & $5.2 \%$ & $31 \%$ & $8 \%$ & 107 \\
\hline
\end{tabular}

Table 4. Proportion of the surface of grain boundaries covered by precipitates and proportion of spherical precipitates for both AC and WQ conditions. 